appreciable improvement. This is an uncommon disease, however, and any further advances seem likely to come only from multicentre studies.

\footnotetext{
References

${ }^{1}$ Steinberg BM, Topp WC, Schneider PS, Abramson AL. Laryngeal papillomavirus infection during clinical remission. $N$ Engl J Med 1983;308:1261-4.

2 Lancaster W, Jenson AB. Evidence for papillomavirus genusspecific antigens and DNA in laryngeal papillomas. Intervirology 1981;15:204-12.

${ }^{3}$ Multiple papillomas of the larynx in children. [Editorial]. Lancet $1981 ; \mathrm{i}: 367-8$.
}

${ }^{4}$ Robbins KT, Howard D. Multiple laryngeal papillomatosis requiring laryngectomy. Arch Otolaryngol 1983;109:765-9.

5 Pritchard J, Eggerding C, Evans JNG, et al. Treatment of laryngeal papillomatosis. Lancet 1980 ;ii: 1383 .

6 Geopfert H, Gutterman JU, Dichtel WJ, Sessions RB, Cangir A, Sulek M. Leukocyte interferon in patients with juvenile laryngeal papillomatosis. Ann Otol Rhinol Laryngol 1982;91:431-6.

Correspondence to Dr W A Hendrickse, Department of Immunology, Institute of Child Health, 30 Guilford Street, London WCIN 1EH.

Received 8 November 1984

\title{
International trends in hospital admission rates for asthma
}

\author{
E A MITCHELL
}

Department of Health, South Auckland Health District, New Zealand

SUMMARY Trends in annual hospital admission rates for asthma in the 0 to 14 year age group were examined in New Zealand, England and Wales, the United States, Canada, and Australia. There has been a striking increase in hospital admissions for asthma in children in all these countries since the mid 1960s.

Hospital admission rates for asthma have increased noticeably since the mid 1960 s in New Zealand. ${ }^{1}$ In the 0 to 14 year age group admissions have increased 10 fold in 15 years (63 per 100000 in 1966 to 629 per 100000 in 1981). An increase in hospital admissions for asthma in children in England and Wales has also been noted. ${ }^{2}$ As part of an investigation into possible explanations for this increase, trends in annual hospital admission rates for asthma in New Zealand children were compared with those of other countries.

\section{Methods}

Hospital admission data for asthma (ICD Code 493) for the 0 to 14 year age group were obtained for New Zealand, Canada, the United States, England and Wales, and Australia. Strictly speaking hospital admissions are discharges from or deaths in hospital for all countries examined, except the United States where the data refer to discharges from hospital. This difference is unimportant as asthma deaths in hospital are rare events compared with asthma admissions. The data from New Zealand and Canada are based on all admissions. The data from England and Wales are based on a $10 \%$ sample of inpatient records from National Health Service hospitals. The United States data are based on a sample of short stay general and specialty hospitals, and in 1980 the sample was approximately $0.5 \%$ of total admissions. Australia does not collect national statistics on hospital admissions, however, these statistics are collected from all hospitals in the states of Queensland and Tasmania, and are reported separately. The data were available for New Zealand from 1952 to 1981, for Canada from 1960 to 1978, for the United States from 1965 to 1980, for England and Wales from 1957 to 1981, for Tasmania from 1969 to 1980, and for Queensland from 1963 to 1980. As changes in the population may have occurred over the time period, the data were expressed as admission rates per 100000 population of age 0 to 14 years.

\section{Results}

The Figure shows the annual rate of hospital admission for the 0 to 14 year age group for these countries. All countries have shown a striking increase with time, the increase seeming to begin in the mid to late 1960s. In New Zealand the hospital admission rate for the 0 to 14 age group has increased 10 fold in 15 years. England and Wales have shown a sixfold increase, the United States a 


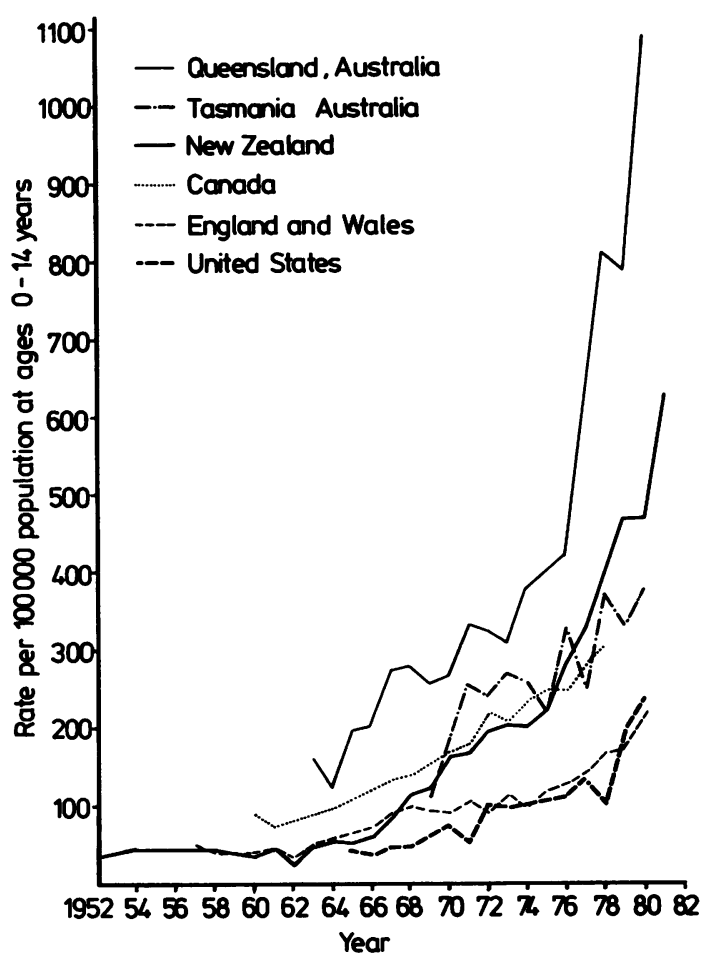

Figure Hospital admission rates for asthma in the 0 to 14 year age group for New Zealand, England and Wales, the United States, Canada, and Queensland and Tasmania (Australia).

threefold increase, Canada a fourfold increase, Tasmania a threefold increase, and Queensland an eightfold increase. The rate of increase in hospital admission does not seem to be slowing.

\section{Discussion}

This study has shown a noticeable increase in hospital admissions for asthma in the 0 to 14 year age group in all countries examined. Caution must be exercised when comparing admission rates between countries as different sampling methods are used, however, this would not account for the trends seen within each country, which seem real. The countries examined have similarities: the predominant ethnic group in each is Caucasian and they share a similar western culture. Admission rates have increased for both the 0 to 4 and 5 to 14 year age group in both England ${ }^{2}$ and New Zealand, ${ }^{3}$ and the increase has been greater in the 0 to 4 year age group.
Changes in ICD coding of asthma as a possible explanation for these trends have been examined previously. ${ }^{1}$ If changes in classification or diagnostic fashions are important one would expect to see a reciprocal decline in other respiratory conditions. This has been examined in detail in New Zealand ${ }^{1}$ and in England and Wales. ${ }^{2}$ In both countries neither the numbers nor direction of the trends in other respiratory conditions in children could account for the considerable increase in hospital admissions seen.

There are a number of possible explanations for these trends:

(1) The prevalence of asthma has increased in the community. Although the prevalence of asthma has approximately doubled in 10 years in New Zealand, ${ }^{4}$ this could only account for part of the increase in hospital admissions.

(2) An increase in the number of admissions per patient. Readmissions have increased in both England ${ }^{25}$ and New Zealand, ${ }^{3}$ but this would only account for approximately $10 \%$ of the total increase in admissions in New Zealand. The noticeable increase in admissions is primarily due to an increase in the number of individual asthmatic patients admitted each year.

(3) Hospital admission criteria have changed so that more mild cases are now admitted than previously. In England there seems to have been a shift in the care of asthmatic patients from primary care towards the hospital. ${ }^{5}$ The number of self-referred patients increased between 1970 and 1978 and these patients had less severe asthma on admission than patients referred by their general practitioner. Overall, however, the degree of severity on admission did not change.

(4) The frequency or severity, or both, of asthma has increased so that asthmatics are more likely to have more severe attacks of asthma leading to more admissions to hospital.

(5) The medical management of asthma has changed and this in some way results in more admissions. Sales of drugs for asthma have increased in New Zealand, Australia, and the United Kingdom. ${ }^{6}$ This suggests that more asthmatics are now receiving drugs or that asthmatics are now receiving more drug treatment for asthma, or both. More effective asthma treatment is now available for children, and yet this group has experienced the largest rise in admissions and increasing readmission rates.

The number of hospital admissions due to asthma in children and the considerable increase in admissions seen in all countries examined indicates that asthma is a major health problem for the child, its family, and the community. 
I thank the staff of the National Health Statistics Centre (New Zealand), Statistics Canada, National Centre for Health Statistics (United States), Office of Population Censuses and Surveys (England and Wales), and the Australian Bureau of Statistics. Permission to publish from the Director General of Health is acknowledged.

\section{References}

1 Jackson RT, Mitchell EA. Trends in hospital admission rates and drug treatment of asthma in New Zealand. NZ Med J 1983;96:727-9.

2 Anderson HR. Increase in hospitalisation for childhood asthma. Arch Dis Child 1978;53:295-300.

${ }^{3}$ Mitchell EA, Cutler DR. Paediatric admission to Auckland hospital for asthma from 1970-1980. NZ Med J 1984;97:67-70.
${ }^{4}$ Mitchell EA. Increasing prevalence of asthma in children. $N Z$ Med J 1983;96:463-4.

5 Anderson HR, Bailey P, West S. Trends in the hospital care of acute childhood asthma 1970-8: a regional study. $\mathrm{Br}$ Med $J$ 1980;281:1191-4.

${ }^{6}$ Keating G, Mitchell EA, Jackson R, Beaglehole R, Rea H. Trends in sales of drugs for asthma in New Zealand, Australia and the United Kingdom, 1975-81. Br Med J 1984;289:348-51.

Correspondence to Dr E A Mitchell, Department of Health, South Auckland Health District, Private Bag, Manukau City, New Zealand.

Received 20 November 1984

\section{Modification of the $\alpha_{1}$-antitrypsin phenotype in neonatal hepatitis}

\section{A A ATTENBURROW}

Neonatal Unit, Derby City Hospital

SUMMARY Two cases of neonatal hepatitis are described, one related to cytomegalovirus infection and the other idiopathic. In both infants a transient abnormality of the $\alpha_{1}$-antitrypsin phenotype, inconsistent with the parent's phenotypes, reverted to normal during the convalescent phase of the illness.

\section{Case 1}

A girl of 36 weeks' gestation, who weighed only $1015 \mathrm{~g}$ at birth, developed a conjugated hyperbilirubinaemia from her third day of life. Her mother had had a non-specific viral illness with a rash at about 24 to 26 weeks' gestation.

Investigation showed evidence of cytomegalovirus infection in urine culture and throat swab. Both mother and child had a cytomegalovirus titre of 40 by complement fixation. Other virology and toxoplasma titres were negative. In addition she had an $\alpha_{1}$-antitrypsin titre of $1.7 \mathrm{~g} / 1$ (normal range 1.8 to 3.0 $\mathrm{g} / \mathrm{l}$ ) with a $\mathrm{P}_{\mathrm{i}} \mathrm{MZ}$ phenotype, despite both parents being $\mathrm{P}_{\mathrm{i}} \mathrm{M}$. She reverted to a $\mathrm{P}_{\mathrm{i}} \mathrm{M}$ phenotype by the age of 11 months.

Her developmental progress has been mildly delayed with bilateral hearing impairment and poor growth. There is no evidence of persisting hepatic pathology at the age of 2 years.

\section{Case 2}

A boy of 33 weeks' gestation, who weighed only $780 \mathrm{~g}$ at birth, developed a conjugated hyperbili- rubinaemia from his eighth day of life. His mother had sickle cell disease and had required the transfusion of $19 \mathrm{U}$ of blood during pregnancy. She had had transient jaundice with severe itching at 26 weeks' gestation.

Investigation showed a normal hepatic ultrasound, negative virology and toxoplasma titres, and negative urine culture for cytomegalovirus. The urine showed no notable increase in reducing substances. His $\alpha_{1}$-antitrypsin value was $1.3 \mathrm{~g} / 1$ (normal range 1.8 to $3.0 \mathrm{~g} / \mathrm{l}$ ) with a $\mathrm{P}_{\mathrm{i}} \mathrm{MZ}$ phenotype. His parents' phenotypes were $\mathrm{P}_{\mathrm{i}} \mathrm{M}$. During the convalescent phase, at the age of 10 months, when his liver function tests had returned to normal, his phenotype reverted to $\mathrm{P}_{\mathrm{i}} \mathrm{M}$ with an $\alpha_{1}$-antitrypsin value of $1.9 \mathrm{~g} / \mathrm{l}$.

He has persisting poor growth, but his development seems to be progressing satisfactorily.

Alpha $_{1}$-antitrypsin phenotyping was performed in both cases by isoelectric focussing on an acrylamide gel.

\section{Discussion}

Alpha $_{1}$-antitrypsin is a protease inhibitor. Deficiency of this protein may be associated with neonatal hepatitis in addition to hepatic cirrhosis ${ }^{12}$ and pulmonary emphysema. ${ }^{3}$

Phenotypic alletes of $\alpha_{1}$-antitrypsin are classified by Latin letters on the basis of their electrophoretic mobility on starch gel electrophoresis. $P_{1} M$ is the phenotype associated with normal $\alpha_{1}$-antitrypsin values. Subjects with $\mathrm{P}_{\mathrm{i}} \mathrm{ZZ}$ phenotype have only $15 \%$ of normal activity, and are more prone to 